ARAŞTIRMA/RESEARCH

\title{
Intrakranial kitle cerrahisinde anestezi uygulamaları: retrospektif çalışma
}

Anesthesia practices in intracranial mass surgery: a retrospective study

Özlem Özmete' ${ }^{1}$ Anış Arıboğan ${ }^{1}$

${ }^{1}$ Başkent Üniversitesi Tip Fakültesi, Adana Uygulama ve Araştırma Merkezi, Anesteziyoloji ve Reanimasyon Anabilim Dalı, Adana, Turkey

\begin{abstract}
Cukurova Medical Journal 2017;42(1):86-91.
Abstract

Purpose: The aim of this retrospective study was to present our evaluate anesthesia experience in patients who underwent intracranial tumor surgery and to discuss the current literature on the perioperative management.

Material and Methods: ASA risk classification I-III 112 patients between the ages of 3-78 were evaluated retrospectively who underwent intracranial mass surgery between the years 2015-2016. Anesthesia registration forms, patient files and hospital computer system was used.for data. The demographic characteristics of patients, anesthetic management, and postoperative data were recorded.

Results: The age of patients ranged from 3-78 years and $57.1 \%$ of them were men. Masses were localized in supratentorial area in $87.5 \%$ (98) of cases. Mean operation time was 184 minutes, mean length of intensive care unit was 3 days and length of hospital stay was 7 days. Common vomplications seen during intraoperative period were tachycardia $(5.4 \%)$, bradycardia $(3.6 \%)$, hypertension $(3.6 \%)$ and hypotension $(1.8 \%)$. In the following days, 13 $(11.6 \%)$ patient received repeated operation. There was not mortality.

Conclusion: Several anesthetic techniques may be used successfully to provide anesthesia for resection of intracranial mass surgery. To reduced morbidity and mortality, the possible complications must be recognized and treated early with invasive monitoring, strict

Öz

Amaç: $\mathrm{Bu}$ retrospektif çalşmada hastanemizde intrakranial kitle cerrahisi uygulanan hastalardaki anestezi deneyimimizin değerlendirilmesi ve perioperatif yönetimin literatür eşliğinde tartışılması amaçlanmıştır.

Gereç ve Yöntem: 2015-2016 tarihleri arasında intrakranial kitle cerrahisi geçiren yaşları 3 ile 78 arasında ASA risk siniflamas1 I-III olan 112 hasta retrospektif olarak değerlendirildi. Veriler için anestezi kayıt formları, hasta dosyaları ve hastane bilgisayar sistemi kullanild. Hastaların demografik özellikleri, anestezi yönetimi ve postoperatif bilgileri kaydedildi

Bulgular: Hastaların yaş aralığı 3 ile 78 arasında değiştiği ve \%57.1'nin erkek olduğu tespit edildi. 98 (\%87.5) hastanın kitlesi supratentorial bölgede iken 14 (\%12.5)'nin infratentorial bölgede lokalize olduğu saptandi. Ortalama operasyon süresi 184 dakika, ortalama yoğun bakımda kalıș süresi 3 gün, hastanede kalış süresi 7 gündür. İntroperatif dönemde görülen komplikasyonlar arasında taşikardi (\%5.4), bradikardi (\%3.6), hipertansiyon (\%3.6) ve hipotansiyon (\%1.8) yer almaktadır. Takiplerde 13 (\%11.6) hastanın tekrar operasyona alındi. Preoperatif ve postoperatif dönemde ölüm ile karşılașılmadı

Sonuç: İntrakranial kitle cerrahisi için nöroaanestezi uygulamalarında çeşitli anestezi teknikleri başarıyla kullanılabilir. İnvaziv monitorizasyon, sıkı hemodinami ve kan gazı takibi ile olası komplikasyonlar erken fark edilerek mortalite ve morbidite azaltılabilir.
\end{abstract} hemodynamics and blood gas monitoring.

Key words: Intracranial mass surgery, craniotomy, neuroanesthesia

\section{GİRİŞ}

İntrakraniyal tümörlerin lokalizasyonu yaşa bağlı olarak değișmektedir. Yetișkinlerde beyin

Anahtar kelimeler: İntrakranial kitle cerrahisi, kraniotomi, nöroanestezi

tümörlerinin 2/3’ü supratentorial bölgede yerleşirken, çocuklarda 2/3'ü infratentorial bölgede yer alır ${ }^{1}$. Intrakraniyal kitle (İKK) cerrahisi uygulanacak olan hastaların mevcut intrakraniyal Yazışma Adresi/Address for Correspondence: Dr. Özlem Özmete, Başkent Üniversitesi Tip Fakültesi, Adana Uygulama ve Araştırma Merkezi, Anesteziyoloji ve Reanimasyon Anabilim Dalı. E-mail: ozlemyilma@yahoo.com Geliş tarihi/Received: 14.06.2016 Kabul tarihi/Accepted: 14.07.2016 
patolojisi nedeniyle intrakraniyal kompliyansı bozulmuş veya kafa içi basıncı artmış olabilir. Bunlara ek olarak cerrahi ve anestezi sırasındaki çeșitli ağrılı uyaranlarla kafa içi basıncının daha fazla artacağ1 bilinmektedir. Özellikle çivili başlık uygulanmas1, laringoskopi, cilt insizyonu sirasinda görülen kalp hızı ve kan basıncındaki yükselme, kafa içi basıncında ani ve tehlikeli artışlarla sonuçlanabilir ${ }^{2}$.

$\mathrm{Bu}$ ameliyatlarda anestezistin primer amacı beynin fizyolojik koşullarını sürdürmektir. Bunun için de beynin ihtiyac1 olan perfüzyon basıncinın sürdürülmesi gerekmektedir. Yeterli serebral perfüzyon basincı (SPB) ortalama arteryel basincin stabil olmasına ve kafa içi basıncının normal olmasına bağlıdır ${ }^{3}$. Cerrahinin ise anesteziden beklentisi; tümörün rahat çıkmasına izin verecek beyin kompliansını sağlamak, gerektiğinde kranial sinirlerin elektrofizyolojik monitorizasyonu, operasyon sonrası erken nörolojik değerlendirmeye izin verecek bilinç düzeyi, postoperatif stabil solunum ve dolaşım parametreleri ve kan kaybının karşılanmasıdır.

$\mathrm{Bu}$ çalıșma ile hastanemizde son bir yıl içinde intrakranial kitle cerrahisi nedeniyle nöroanestezi uygulanan hastaların retrospektif olarak değerlendirilmesi, sonuçların literatür eşliğinde tartışılması amaçlanmıştır.

\section{GEREÇ VE YÖNTEM}

Çalışma Bașkent Üniversitesi Klinik Araştırmalar Etik Kurulu'ndan 25.04.2016 tarihinde (Proje no: KA16/168) izin alındiktan sonra Başkent Üniversitesi Tip Fakültesi Adana Uygulama ve Araştırma Merkezinde Ocak 2015-Ocak 2016 tarihleri arasinda intrakranial kitle cerrahisi uygulanan hastalar çalışmaya alınmıştır. Çalışma kliniğimiz anestezi kayıt formları ve nükleus medikal bilgi sistemi kullanılarak retrospektif olarak gerçekleştirilmiştir.

Ameliyat öncesi kayıtlarından; hastaların demografik özellikleri, ASA (American Society of Anesthesiologist) siniflamas1 ve kitlenin lokalizasyonu kaydedilmiştir.

Ameliyat sırasındaki kayıtlarından; uygulanan monitorizasyon ve anestezi şekli (inhalasyon veya intravenöz anestezi), kullanılan anestezik ve antiödem ilaçlar, girişim süresi, hastanın cerrahi sırasındaki pozisyonu, kitlenin lokalizasyonu, verilen sıvılar ve miktarı, kan ve kan ürünleri miktarı, operasyon sırasında görülen komplikasyonlar, uygulanan tedaviler ve sonuçları kaydedildi.

Postoperatif dönem kayıtlarından; yoğun bakımda kalış süresi, hastanede kalış süresi, postoperatif mortalite ve nedenleri ile olasi anestezi uygulamalarına bağlı faktörler ayrıntılı olarak incelendi.

Anestezi yönetiminde standart anestezi monitorizasyonu sonrası (EKG, noninvazif kan basinc1 takibi, nabiz oksimetresi, end tidal karbondioksit ve 1s1 probu) uygun olan hastalara iv midazolam ile premedikasyon uyguland. Hastaların başının 30-45 derece yukarda iken (5 mg kg-1) sodyum tiyopental veya propofol (2-3 mg kg-1), fentanil $(2 \mu \mathrm{g} \mathrm{kg-1)}$ ve roküronyum bromür $(0,6 \mathrm{mg}$ kg-1) ile anestezi indüksiyonu uyguland. Entübasyon sonras1 hastalara radiyal arterden invaziv arteriyel kateterizasyon, sağ internal juguler venden santral venöz kateterizasyon ve mesane kateterizasyonu uygulandı. Anestezi idamesinde \% 50 hava \% 50 oksijen içinde total intravenöz anestezi (TIVA) (propofol-fentanil infüzyonu; 5-6 mg kg-1 st-1, $1-2 \quad \mu g \quad k g-1 \quad$ st-1) veya $\% \quad 2$ konsantrasyonda sevofluran veya \% 1.5 konsantrasyonda izofluran verildi. Solunum frekans1 hasta yaşı ile uyumlu, EtCO2 30-35 mmHg arasında ve tidal volüm 6-8 ml kg-1 olarak ayarlandı. Tüm hastalara elastik veya pnömotik bacak bandajlar1 uygulandi. Hastalara uygun poziyon verildikten sonra pleksus hasarlarından korunmak için yumuşak destek, eklemlerin nötral pozisyonunu korumaya, gözler ve burun gibi uç noktaları korumaya özen gösterildi. Cerrahın isteğine bağlı olarak istenen hastalara nörofizyolojik monitorizasyon yapıldı. Saat başı kan gazı örneklemeleri ile asit baz dengesi ve hemoglobin takibi yapilarak hematokritin $\geq 28$ olması hedeflendi. Anestezi uygulamasi esnasinda hemodinamik verilerin ve kanama takibinin yanı sıra idrar output takibi yapıldı. Tüm olgular için, hipotansiyon geliştiğinde (ortalama arter basincı $(\mathrm{OAB}) \quad<50 \mathrm{mmHg}$ ) iv siv1 yüklemesi, yanıt alınamazsa efedrin, bradikardi geliştiğinde (kalp atım hızı $(\mathrm{KAH})<50$ atım dk-1) ise iv atropin ile tedavi edilmesi planlandi. Olgularda OAB'nin bazal değerin $\% 20$ 'sinden fazla artması durumunda ise ek fentanil, taşikardi geliştiğinde (kalp atım hızı $(\mathrm{KAH})>100$ atım dk-1) ise metoprolol iv uygulandı. Kilolarına uygun şekilde yapılan bu medikasyonlar ve komplikasyonlar anestezi gözlem kağıdına kaydedildi. Operasyon bitimine bir saat kala iv $1 \mathrm{mg}$ 
kg-1 tramadol ve $10 \mathrm{mg} \mathrm{kg}-1$ parasetamol tüm hastalara rutin olarak uygulandı. Cilt sütürasyonu sırasında tüm anestezik ajanlar durdurulup \%100 oksijen ile ventilasyona geçildi. Ameliyat sonunda tüm hastalara $0.015 \mathrm{mg} \mathrm{kg}-1$ atropin ve $0.05 \mathrm{mg} \mathrm{kg}-1$ neostigmin iv uygulandi. Ekstübasyon sonrasinda ise hastaların tamamı ileri takip amacıyla yoğun bakım ünitesine devir edildi.

\section{İstatistiksel analiz}

Verilerin analizi Statistical Package for the Social Sciences (SPSS) for Windows 17 (Chicago IL., USA) paket programında yapıldı. Tanımlayıcı istatistikler sürekli değişkenler için ortalama ve standart sapma veya minimum-maksimum olarak kategorik değişkenler ise olgu sayısı ve (\%) biçiminde gösterildi.

\section{BULGULAR}

Bir yıllık periyodda intrakranial kitle cerrahisi nedeniyle 112 hasta çalışma kapsamına alınmış olup hastaların demografik verileri (yaş, cinsiyet, boy, vücut ağırlı̆̆1 ve ASA sinıflamasi) Tablo I'de gösterilmiştir. Kitlelerin $\% 87.5$ 'i supratentorial yerleşimli iken, \%12.5'inin infratentorial bölgede lokalize olduğu tespit edildi. Operasyon süresi ortalama 183 dakika olup hastaların intraoperatif ve postoperatif özellikleri Tablo II de belirtildi. Anestezi indüksiyonu için propofol (\%90.2), sodyum tiyopental (\% 9.8), roküronyum $(\% 100)$ ve fentanil (\%100); anestezi idamesi için sevofluran (\%49.1), izofluran (\%18.8) veya TiVA (\%32.1) uygulandığı tespit edildi. KİB artışını önlemek için mannitol (\%100), deksametazon $(\% 92)$ ve furosemid (\%15.2) kullanıldığı saptandı. İntraoperatif dönemde hastalara uygulanan ortalama kristalloid miktarı 1083 $\mathrm{mL}$, kolloid miktarı ise $174 \mathrm{~mL}$ olarak tespit edildi (Tablo II).

Postoperatf bulantı kusma (POBK) profilaksisi için tüm hastalara $(\% 100)$ metoklopramid iv yoldan uyguland1. Intraoperatif dönemde en s1k görülen komplikasyonun taşikardi (\%5.4) olduğu belirlendi. Diğer komplikasyonlar Tablo III da gösterildi. Hiçbir hastada klinik olarak saptanabilir venöz hava embolisi (VHE) ve aritmi gözlenmedi. İntroperatif 7 hastaya eritrosit süspansiyonu, 4 hastaya ise taze donmuş plazma uygulandığı saptandı.

Hastaların tamamı ekstübe olarak yoğun bakıma çıartılmış olup postoperatif dönemde ortalama 3 gün yoğun bakımda kaldığ1 ve hiçbirinin mekanik ventilasyon ihtiyacı olmadığı saptandı. 112 hastanın tamamının yoğun bakımdan servise gönderildiği ancak takiplerde 13 (\%11.6) hastanın tekrar operasyona alındığı ve hastaların tamamının sağlıklı şekilde hastaneden taburcu edildiği tespit edildi.

Tablo 1. Hastaların demografik verileri

\begin{tabular}{|l|c|c|}
\hline & Minimum-maksimum / n & Mean \pm SD \\
\hline Yaş (y1) & $3-78$ & $48.63 \pm 17.69$ \\
\hline Cinsiyet (E/K) & $64 / 48$ & \\
\hline Vücut ağırlı̆g1 (kg) & $17-110$ & $72.50 \pm 16.50$ \\
\hline Boy (cm) & $87-190$ & $165.41 \pm 15.50$ \\
\hline ASA ( I / II/ III) & $11 / 55 / 46$ & \\
\hline
\end{tabular}

Veriler minimum-maksimum, olgu sayısı (n) veya mean \pm SD olarak belirtilmiştir.; ASA: American Society of Anesthesiologist

Tablo 2. Hastaların intraoperatif ve postoperatif özellikleri.

\begin{tabular}{|l|c|c|}
\hline & Minimum-maksimum / n & Mean \pm SD \\
\hline Operasyon süresi (dk) & $120-360$ & $183.79 \pm 43.05$ \\
\hline Pozisyon (supin/oturur/pron) & $89 / 14 / 9$ & \\
\hline Kanama miktarı (mL) & $50-2000$ & $241.07 \pm 293.33$ \\
\hline Kristalloid miktarı (mL) & $300-4000$ & $1083.03 \pm 510.05$ \\
\hline Kolloid miktarı (mL) & $0-1000$ & $174.10 \pm 264.65$ \\
\hline Yoğun bakımda kalış süresi (gün) & $1-11$ & $3.26 \pm 1.70$ \\
\hline Hastanede kalış süresi (gün) & $3-35$ & $7.73 \pm 4.08$ \\
\hline
\end{tabular}

Veriler minimum-maksimum, olgu sayısı (n) veya mean \pm SD olarak belirtilmiştir

Table 3. Hastalarda görülen introperatif komplikasyonlar 


\begin{tabular}{|l|c|}
\hline & $\mathbf{n ~ ( \% )}$ \\
\hline Taşikardi & $6(\% 5.4)$ \\
\hline Bradikardi & $4(\% 3.6)$ \\
\hline Hipertansiyon & $4(\% 3.6)$ \\
\hline Hipotansiyon & $2(\% 1.8)$ \\
\hline Aritmi & $0(\% 0)$ \\
\hline Venöz hava embolisi & $0(\% 0)$ \\
\hline
\end{tabular}

Veriler olgu sayısı (n) ve yüzde (\%) olarak belirtilmiștir.

\section{TARTIŞMA}

Beyin tümörleri, tüm hastalıklar içinde en dramatik türlerden birini oluşturmaktadır. Çocukluk çağının en sık rastlanan ikinci malignite iken erişkinlerde primer beyin tümörleri en s1k rastlanan 6. malinite olarak karşımıza çıkmaktadır ${ }^{4}$.

Nöroşirurji girişimleri genellikle uzun ve özel pozisyon gerektiren girișimlerdir. Bazı durumlarda s1v1 kısitlamas1, hiperventilasyon, özel monitorizasyon gerekebilir ve bu nedenlerle hastalar preoperatif iyi değerlendirilmelidir. Yaş, yandaş hastalık, ASA skoru, kullanılan ilaçlar yanında nörolojik muayene, bilinç durumu, KİB, fokal nörolojik hasarların tespiti yapılmalıdır. İntrakraniyal hipertansiyondan süpheleniliyorsa solunumu her an bozulabileceği için bu hastalara premedikasyondan kaçınılmalıdır veya verilecek ise sıkı takip yapılmalıdır. Çalışmamızda uygun hastalara (\%77.7) monitorizasyon öncesi premedikasyon amacıyla iv 1-3 mg midazolam uygulanmış olup solunum depresyonu ile karşılaşılmadığ1 tespit edildi.

Intrakraniyal kitle cerrahisi, preoperatif dönemden bașlayıp postoperatif yoğun bakım sürecini de kapsaması nedeniyle özellik taşıyan bir cerrahi türüdür. İntrakraniyal kitle cerrahisinde kullanılacak anestezik ajanın serebral kan akımı ve serebral metabolik oksijen tüketimini sürdürmesi ve/veya azaltmas1, intrakraniyal basinc1 azaltmas1, serebral koruyucu etkisinin olması, antikonvülzan etkisinin olmas1, majör organ sistemlerini etkilememesi, etkisinin hızlı başlaması, erken derlenme sağlaması gerekmektedir. Sodyum tiyopental serebral kan akımında (SKA) azalma ve antikonvülzan olma gibi özellikleri nedeniyle nöroanestezide en çok kullanılan indüksiyon ajanı olmuştur. Lunn ve arkadaşlarının 108878 hastayı kapsayan çalışmasında anestezi indüksiyonunda $\% 82$ oranında sodyum tiyopental kullanıldığ1 belirtilmiştir ${ }^{5}$. Çalışmamızda ise serebral metabolizmayı yavaşlatması, SKA ve KİB'1 azaltması nedeniyle $101 \quad(\% 90.2)$ hastaya propofol, $11(\% 9.8)$ hastaya ise sodyum tiyopental ile anestezi indüksiyonu yapıldığı tespit edildi.

Laringoskopi ve endotrakeal entübasyon sirasinda olusan kardiyovasküler yanıt özellikle kardiyak rezervi düşük ve intrakraniyal problemi olan olgularda istenmeyen bir etkidir. Uygulanan anestezi yönteminin bu hiperdinamik yanıtı azaltması önemlidir. İdeal nöroanestezik ajanın en önemli kriterlerinden biri de erken derlenme sağlamasıdır. Sevofluran ve izofluran nöroanestezide en fazla kullanılan inhalasyon ajanlarıdır ${ }^{6}$. Ancak bu ajanların serebral metabolik hizda yaptıkları azalmayla beraber oluşturdukları serebral vazodilatasyon ile serebral kan akımını ve intrakraniyal basınc1 arttırdıkları bilinmektedir. Bununla beraber tek başlarına kullanıldıklarında trakeal entübasyon, laringoskopi, cilt insizyonu gibi ağrlli uyaranlara stres cevab1 baskilamakta yetersiz kalmaktadırlar. İnhalasyon ajanlarının serebral sistem üzerine olumsuz etkilerini azaltmak için adjuvan ilaçlar (opioidler, NMDA antagonistleri, benzodiyazepinler) kullanılmaktadır. Literatürde de bu amaçla remifentanil, fentanil, deksmedetomidin kullanıldığı çeşitli klinik çalışmalarda gösterilmiştir ${ }^{7}$. Son yıllarda nörosirurji girisimlerinde inhalasyon ajanlarinın serebral yan etkilerini azaltmak amacıyla intravenöz anestezi teknikleri kullanılmaya başlanmışıır ${ }^{8-10}$. TíVA tekniğinde; propofol İKB'n1 azaltmas1, otoregülasyonu bozmaması serebral damar direnci ve serebral arteriovenöz oksijen farkını etkilememesi, uzun süreli infüzyonlardan sonra bile hızlı derlenme sağlaması nedeniyle tercih edilmektedir ${ }^{9,10}$. Çalışmamızda da anestezi idamesinde sevofluran (\%49.1), izofluran (\%18.8) inhalasyon anestezisi ve TIVA (\%32.1) anestezisi uygulandığ1 saptandi. Literatürde propofol ve sevofluran anestezisi sonrasi derlenme sürelerini karşılaştıran birçok çalışma ve farklı sonuçlar mevcuttur ${ }^{11-13}$. Yli-Hankala ve arkadaşlar1 ${ }^{14}$ bispektral indeks kontrolü altında inhalasyon ve intravenöz anestezi sonrası derlenme süreleri açısından gruplar arasında istatistiksel bir fark 
olmadığını bildirmiştir. Sneyd ve arkadaşları elektif intrakranial kitle cerrahisi için 52 hastayı kapsayan çalışmalarında inhalasyon ve intravenöz anestezi uygulaması sonrası hastaların ekstübasyon zamanı ve komutlara uyma sürelerinin benzer olduğunu belirtmişlerdir ${ }^{15}$.

Posterior fossa cerrahisinde supratentoryal cerrahiden farklı olarak hemodinamik problemlerin daha sık görüldüğü bilinmektedir. Sneyd ve arkadaşlarının çalışmasında propofol grubu ile kiyaslandığında sevofluran grubu hastalarda daha fazla posterior fossa cerrahisi uygulandığ1 ve intraoperatif hemodinamik instabilite problemi yaşanmadığ1 belirtilmiştir ${ }^{15}$. Çalışmamızda da posterior fossa cerrahisi için 4 hastaya propofol, 10 hastaya sevofluran anestezi uygulanmış olup hiçbir hastada intraoperatif hemodinamik bozukluk tespit edilmemiştir.

İntrakranial kitle cerrahisi cerraha kolay çalışma imkanı sağlayacak şekilde supin, pron, oturur ve yan gibi farklı pozisyonlarda yapılabilmektedir. Yeğin ve arkadaşlarının $^{16}$ intrakranial kitle nedeniyle 1103 vakayı kapsayan çalışmasında hastalara en sık supin $(\% 64,5)$ pozisyon verildiği, Erdinçler ve arkadaşlarının $^{17}$ yaptıkları çalışmada ise cerrahi sirasinda hastalarin \%74,1'ine supin, \%24,9'una oturur, \%1'ine yar1 yan pozisyon verildiği bildirilmiştir. Literatürle uyumlu olarak çalışmamızda intrakranial kitle cerrahisi için hastalara en sık supin (\%79.5) pozisyonunun tercih edildiği belirlenmiştir.

Ameliyat süresi yapılan operasyonun tipi, cerrahi teknikler, hastanin fiziki durumu, anestezist ve cerrahın becerisi gibi faktörlere bağlıdır. Türe ve arkadaşları ${ }^{18}$ yaptıkları çalışmada anestezi süresinin ortalama 342 dakika, Yeğin ve arkadaşlar1 ${ }^{16}$ ise ortalama 217dakika olduğunu bildirmişlerdir. Çalışmamızda anestezi süre ortalaması 184 dakika olarak bulundu ve anestezi süresi uzun olan hastalarda daha sık komplikasyon yaşandığı tespit edildi.

Kraniyotomi sonrasında görülen ağrının klasik görüş olarak az olduğu kabul edilir ve genellikle önemsenmemektedir. Ancak düşünülenin aksine kraniyotomi sonrasinda da orta derecede veya ciddi ağrının oldukça yaygin olduğu bildirilmektedir ${ }^{19}$. Analjezik amaçla nonsteroid antiinflamatuar ajanlar, parasetamol, opiodler, vb. ilaçlar uygulanmaktadir ${ }^{19-}$ ${ }^{21}$. Burada en önemli klavuzun hastanın bilinç düzeyi olduğunu düşünmekteyiz. Eğer bilinç açık ve hastanın ağnı algılaması varsa mutlaka postoperatif analjezi uygulanmalıdır. Elektif kraniyotomi uygulanan 52 olguda gerçeklestirilen retrospektif bir çalısmada ilk 24 saatte gözlenen ağrı değerlendirilmis ve operasyon sonrasındaki ilk 2 saat içerisinde $\% 18$ olgu oldukça 1zdırap verici , \%37 olgu şiddetli, \%29 olgu orta dereceli ve \% 4 olgu ise hafif ağrıdan şikayetçi olmuştur. Olguların yalnızca \%12'si kraniyotomiyi takiben 24 saat içerisinde ağn1 tanımlamamıştır ${ }^{22}$. Çalışmamızda tüm hastalara rutin olarak $1 \mathrm{mg} \mathrm{kg}^{-1}$ tramadol ve $1 \mathrm{~g}$ parasetamol iv uygulanmış olup akut postoperatif dönemde ek analjezik ihtiyacı olmadığ 1 tespit edilmiştir.

Pek çok çalışmada sevofluran anestezi sonrası POBK propofol anestezisine göre daha sık olduğu bildirilmiştir. Bizim çalışmamızda, POBK propofol, sevofluran ve izofluran anestezisi alan arasında hiçbir fark olmadığ1 saptandi. Ancak buna neden olarak tüm hastalarımıza iv metoklopramid uygulanmasının etkisi olduğunu düşünmekteyiz.

Cerrahi veya anesteziye bağlı önemli bir neden yoksa intrakranial cerrahi sonrasi tüm hastalar ameliyathanede ekstübe edilmesi erken nörolojik değerlendirme için gereklidir. Ancak büyük tümörler, kanama riski, stabil olmayan hemodinami, beyin sap1 girişimleri erken ekstübasyona izin vermeyebilir. Özellikle yüzeyel anestezi altında yapılan ekstübasyonda hastada intrakraniyal basınç artıs1, intrakraniyal kanama, serebrovasküler olay gibi bir ensefalopati tablosu gelisebilecegi gibi akut sol kalp yetmezliği, pulmoner ödem, miyokard enfarktüsü, gibi organ hasarları da görülebilir. Tüm bu olumsuzlukları önlemek için ekstübasyon öncesi düşük dozda hipnotik, opioid analjezik, lidokain, adrenerjik blokerler uygulanabilir. Çalışmamızda hastaların tamamının ekstübe olarak yoğun bakıma çıkarıldığı tespit edildi.

İlçe ve arkadaşlar1 ${ }^{23}$ çalışmalarında postoperatif yoğun bakımda kalış süresini ortalama 11 gün, Yeğin ve arkadaşlar1 $^{18}$ ise 6 gün olarak bildirmişlerdir. Çalışmamızda ise postoperatif yoğun bakımda kalış süre ortalama 3 gün olarak tespit edilmiştir.

Sonuç olarak intrakranial kitle cerrahisi nedeniyle anestezi yönetiminde hemodinamik stabilitenin sağlanması ve gelişebilecek olası komplikasyonlar nedeniyle sıkı invaziv monitorizasyon yapılması ve postoperatif erken derlenme son derece önem taşımaktadır. $\mathrm{Bu}$ nedenle kullanılacak anestezi yönteminin intrakraniyal basinc1 arttırmamas1, intraoperatif ve postoperatif hemodinamik stabiliteyi koruması ve cerrahi sonrası erken nörolojik 
muayeneye izin verecek güvenli ve hılı uyanma sağlanması biz anestezistlerin asıl hedefi olmalıdır.

\section{KAYNAKLAR}

1. Dunham C. Pediatric brain tumors, a histologic and genetic update on commonly encountered entities. Semin Diagn Pathol. 2010;27:147-59.

2. Charuluxananan S, Kyokong O, Somboonviboon W, Balmongkon B, Chaisomboonpan S. Nicardipine versus lidocaine for attenuating the cardiovascular response to endotracheal intubation. J Anest. 2000;14:77-81.

3. Kayhan Z. Klinik Anestezi, Genişletilmiş 3. Bask1, İstanbul, Logos Yayıncilik, 2004.

4. Stevenson KL. Pediatric brain tumors. J Neuroscience. 2004;1:10-20.

5. Lunn JN, Farrow SC, Fowkes FG, Robertson IB, Samuel P. Epidemiology in anaesthesia. I: Anaesthetic practice over 20 years. Br J Anaesth. 1982;54:803-9.

6. Moshchev DA, Lubnin Alu. Use of sevoflurane in neuroanesthesiology. Anestheziol Reanimatol. 2006;2:25-32.

7. Tanskanen PE, Kytta JV, Randell TT, Aanta RE. Dexmedetomidine as an anaesthetic adjuvant in patients undergoing intracranial tumour surgery:a double-blind, randomized and plasebo-controlled study. Br J Anaesth. 2006;97:658-65.

8. Yamada M, Nishikawa K, Kawahara F, Yoshikawa D, Saito S, Goto F. Anesthetic management for clipping a giant basilar artery aneurysm with moderate hypothermia, extracorporeal circulation assistance, and propofol infusion. J Neurosurg Anesthesiol. 2003;15:274-7.

9. Coles JP, Leary TS, Monteiro JN, Brazier P, Summors A, Doyle P et al. Propofol anesthesia for craniotomy: a double-blind comparison of remifentanil, alfentanil, and fentanyl. J Neurosurg Anesthesiol. 2000;12:15-20.

10. Farling P, Unni A, Young A. Total intravenous anaesthesia for intracranial aneurysm surgery. In Focus on Infusion, Intravenous Anaesthesia (Ed C Prys-Roberts):164-7. London, Current Medical Literature Ltd, 1991.

11. Matsumoto H, Shingu K, Numata K. Total intravenous anesthesia with propofol is advantageous than thiopental-sevoflurane anesthesia in the recovery phase. Masui. 1998;47:1046-58.

12. Ku AS, Hu Y, Irwin MG, Chow B, Gunawardene S, Tan EE et al. Effect of sevoflurane/nitrous oxide versus propofol anaesthesia on somatosensory evoked potential monitoring of the spinal cord during surgery to correct scoliosis. $\mathrm{Br} \mathrm{J}$ Anaesth. 2002;88:502-7.

13. Schmidt J, Fechner J, Fritsch B, Schmitz B, Carbon R, Rösch W et al. Propofol-remifentanil versus sevoflurane-remifentanil for anesthesia for pediatric procedures in infants, children and adolescents. Der Anaesthesist. 2001;50:757-66.

14. Yli-Hankala A, Vakkuri A, Annila P, Korttila K. EEG bispectral index monitoring in sevoflurane or propofol anaesthesia: analysis of direct costs and immediate recovery. Acta Anaesthesiol Scand. 1999;43:545-9.

15. Sneyd JR, Whaley A, Dimpel HL, Andrews CJ. An open, randomized comparison of alfentanil, remifentanil and alfentanil followed by remifentanil in anaesthesia for craniotomy. $\mathrm{Br} \mathrm{J}$ Anaesth. 1998;81:361-4.

16. Yeğin S, Sarıhasan B, Üstün YB, Bilgiç B. 2000-2010 y1lları arasinda intrakranial kitle cerrahisi nedeni ile anestezi uygulanan hastaların retrospektif analizi. Turk J Anaesth Reanim. 2012;40:315-20.

17. Erdinçler P, Dalgıçlar A, Tüzgen S. Posterior fossa analysis tumors of 73 in children cases. Türk Nöroşirürji Dergisi. 2002;12:31-9.

18. Türe H, Koner Ö, Aykaç B, Türe U. Oturur pozisyondaki kraniyotomi operasyonlarında venöz hava embolisinin transözofajiyal eko-kardiyografiyle monitörizasyonu: standart anestezi protokolümüzle prospektif değerlendirme. Türk Anest Rean Der Dergisi. 2010;38:176-83.

19. Güneş Y, Gündüz Y, Özbek H. Kraniyotomilerde analjezi yönetimi. Türk Nörosiriirji Dergisi. 2005;15:305-10.

20. Verchere E, Grenier B, Mesli A, Siao D, Sesay M, Maurette P. Postoperative pain management after supratentorial craniotomy. Neurosurg Anesthesiol. 2002;14:96-101.

21. Unlugenç H, Gunduz M, Guler T, Yagmur O, Isık G. The effect of pre-anaesthetic administration of intravenous dexmedetomidin on postoperative pain in patients receiving patient-controlled morphine. Eur J Anaesthesiol. 2005;22:386-91.

22. Quiney N, Cooper R, Stoneham M, Walters F. Pain after craniotomy: a time for reappraisal? $\mathrm{Br} J$ Neurosurg. 1996;10:295-9.

23. İlçe A, Totur B, Özbayır T. Beyin tümörlü hastaların uluslararası NANDA hemşirelik tanılarına göre değerlendirilmesi: bakım önerileri. J Neurol Sci. 2010;27:178-84. 